\title{
Effect of Glucan on Murine Lupus Evolution and on Host Resistance to Klebsiella pneumoniae \\ Helena A. Harima, ${ }^{1 *}$ Nelson F. Mendes, ${ }^{1}$ Elsa M. Mamizuka, ${ }^{2}$ and Mario Mariano ${ }^{3}$ \\ ${ }^{1}$ Disciplina de Imunologia, Departamento de Microbiologia, Imunologia e \\ Parasitologia da Universidade Federal de São Paulo - Escola Paulista de Medicina, \\ ${ }^{2}$ Departamento de Análises Clínicas e Toxicologia da Faculdade de Farmácia de Universidade de São Paulo, \\ ${ }^{3}$ Departamento de Imunologia do Instituto de Ciências Biomédicas da Universidade de São Paulo, São Paulo, Brazil
}

Glucan is a polysaccharide from the yeast Saccharomyces cerevisiae that stimulates the mononuclear phagocytic system (MPS). NZB/NZW F1 mice were divided into two groups: one group received a subcutaneous injection of $0.5 \mathrm{mg}$ glucan/animal for 1 week, and the other received the same dose for 3 months. No changes were observed in those animals submitted to short-term glucan treatment, whereas animals with active lupus and submitted to long-term glucan administration presented early death, with significant dif- ferences in accumulated mortality rates over 33-37 weeks, when compared to controls. No deaths were observed in lupus mice treated with glucan 24 hours before the induction of septic shock by Klebsiella pneumoniae, in contrast to mortality of $95.3 \%$ in the control group during the follow-up period of 12 days. We conclude that although glucan is able to exacerbate lupus activity, it enhances resistance to infection in lupus mice. J. Clin. Lab. Anal. 11:175-178, 1997. (1997 Wiley-Liss, Inc.

Key words: glucan; lupus; immunomodulation; resistance; Klebsiella

\section{INTRODUCTION}

Both human and murine lupus show B cell hyperreactivity, T-cell regulatory abnormalities, mononuclear phagocytic system (MPS) dysfunction, production of autoantibodies, and immune complexes $(1,2)$. The MPS disorders are characterized by impaired phagocytosis during disease activity (3) and reduced synthesis of tumor necrosis factor (4) and prostaglandins (5).

$\beta-1,3$ glucan is derived from the common yeast Saccharomyces cerevisiae cell wall (6) and influences the host defense mechanisms by means of MPS activation (7-9). Glucan increases the phagocytic function and macrophage proliferation $(7,10)$, modifies the intravascular clearance and tissue distribution of soluble and particulate antigens (11), and induces the production of cytokines (12) and prostaglandins (13). Glucan is able to modify the host response, increasing resistance to infections in normal (14), drug-immunosuppressed, and tumor-bearing animals (15). It is also a reliable adjuvant in experimental vaccines (16) and in the induction of experimental allergic encephalomyelitis in rats (17). Glucan stimulates cell-mediated immunity in mice (18), and at high doses causes early death in a number of mouse strains (19).

The use of glucan to increase the host nonspecific resistance might be indicated in conditions of temporary immunosuppression. However, theoretically, it might potentiate pre-existing autoimmunity. Thus the objective of the present study was to investigate the effect of glucan on the evolution of murine lupus and on the resistance to infection in this disease.

\section{MATERIALS AND METHODS}

\section{Animals}

Adult female NZB/NZW F1 mice bred at the Immunology Department (Institute of Biomedical Sciences, University of São Paulo) were used.

\section{Glucan and Bacteria}

Polysaccharide prepared from Saccharomyces cerevisiae according to Hassid et al. (1941). The concentration of the insoluble preparation was adjusted to $10 \mathrm{mg} / \mathrm{ml}$ in sterile saline.

Klebsiella pneumoniae was provided by the Department of Clinical Analyses and Toxicology (School of Pharmacy, University of São Paulo). The inoculum for intraperitoneal

*Correspondence to: Helena A. Harima, Rua Botucatu, 862 - Edifício de Ciências Biomédicas ( $4^{\circ}$ andar), CEP 04023-900, Caixa Postal 20300, São Paulo, Brazil.

Received 11 October 1996; Accepted 16 October 1996 
challenge was prepared by subculturing $K$. pneumoniae in trypticase-soy broth for 18 hours at $37^{\circ} \mathrm{C}$ in a shaking water bath. The culture was centrifuged for 15 minutes, and the cell pellet was washed three times with buffered saline. Cell concentrations was adjusted by nephelometry.

\section{Experiment 1: Effect of Glucan on Murine Lupus Evolution}

The animals were divided into groups of 2- and 5-monthold mice. The former group included clinically healthy animals in the serologic stage of lupus; the latter consisted of sick animals in the histologic stage of lupus (20). Glucan 0.5 mg administered subcutaneously was injected into each animal and a control group received only saline. Short-term treatment consisted of glucan administration on days zero, 3 , and 7 ( $\mathrm{N}=5-7$ animals). Prolonged treatment consisted of glucan administration on days zero, 3, 7, 30, 60 and $90(\mathrm{~N}=14-16$ animals). These animals were followed until death. Antinuclear antibody (ANA) titers were determined by indirect immunofluorescence (21) in nonautoimmune mouse liver imprints before and 14, 30, 60, and 90 days after treatment. After 30 days, the short-term treated groups were submitted to histological study of the kidney which included young (2 months) and old (5 months) animals.

\section{Experiment 2: Effect of Glucan on Resistance of Lupus Mice to Experimental Peritonitis Induced by Klebsiella pneumoniae}

Female NZB/NZW F1 mice, aged 5 months, were divided into four groups, as follows: Group I-previous treatment with glucan 24 hours before bacterial injection ( $N=22)$, Group II-treatment with glucan immediately after bacterial injection $(\mathrm{N}=21)$, Group III-treatment with glucan 20 hours after bacterial injection (22), Group IV-saline control. Adult male Balb/c mice were used as nonautoimmune controls $(\mathrm{N}=10)$. Each animal was given a single $1.5 \mathrm{mg}$ glucan dose by the intraperitoneal route or saline, and $0.6 \times 10^{8}$ bacteria/ $\mathrm{ml}$ were inoculated by the intraperitoneal route for septic shock induction. The number of deaths was determined on the 14th day of the experiment.

Statistical analysis. Nonparametric methods such as the Mann-Whitney test, Kolmogorov-Smirnow test, Chi-square, Fisher's exact test, and Cox-Mantel test were used.

\section{RESULTS}

\section{Effect of Glucan on Murine Lupus Evolution}

NZB/NZW F1 mice treated with glucan for 1 week and controls, as well as the 2- and 5-month old animals, survived the 1-month period of follow-up. No deaths were observed during the 3-month period among the 2-month old animals treated or not with glucan until they reached 5 months of age. The glucan group had a lifespan of 182.3 days and the con- trols had a life span of 192.5 days. The differences in accumulated death rates by age were not statistically significant. The mean survival of the glucan-treated animals were 34.6 weeks as compared to 36.0 weeks for the controls (Fig. 1).

The 5-month old animals treated with glucan for 3 months presented a mean life span of 70.3 days vs. 115.0 days for the controls. All the animals treated with glucan died within 131 days, whereas $26.6 \%$ of the controls were still alive, one of them having reached 317 days of life. The glucan group showed a tendency to early death, with a mean survival of 31.5 weeks compared to 37.8 weeks for the controls. The difference in accumulated death rate between the glucan group and the control was statistically significant for animals aged 33-37 weeks, since $87.5 \%$ (14/16) deaths were observed in the glucan group and 53.3\% (8/15) among the controls. Fifty percent of the glucan-treated animals, (50\%) died within a 29-33-week period, whereas the controls died within 33-37 weeks (Fig. 2).

Two- to 5-month old animals receiving glucan or saline for a short period of time did not show significant differences in ANA titers. Young healthy animals from both groups showed negative ANA levels. Most of the old and sick animals, glucan-treated as well as the controls, presented 1/10 and 1/320 ANA titers before and at 14 and 30 days. Light microscopy did not reveal any histological kidney abnormality among young female NZB/NZW F1 mice within 30 days. However, only one animal from the 5-month control group developed severe glomerulonephritis at 6 months of age, and most of the old animals showed mild lesions (data not shown).

Two-month-old animals treated or not with glucan for 3 months had negative ANA titers before and after 14, 30, and 60 days of the experiment, but after 90 days, in both groups 8 out of 14 animals showed ANA titers between 1/10 and 1/80.

During the experiment, 5-month-old animals submitted to long-term treatment with glucan or untreated died due to lu-

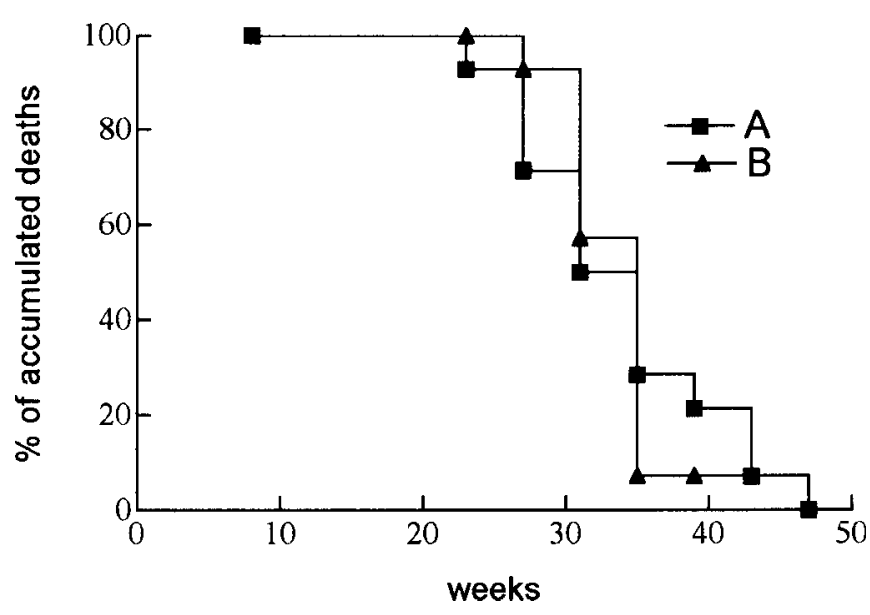

Fig. 1. Effect of glucan on survival of 2-month-old female NBZ/NBW F1 mice A. Glucan group ( $\mathbf{\square})$. B. Saline group $(\boldsymbol{\Delta})$. 


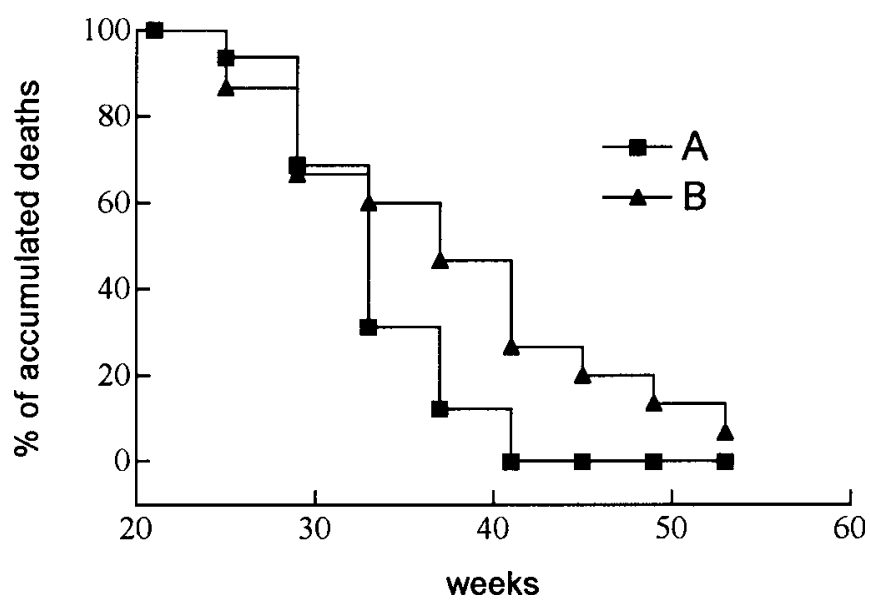

Fig. 2. Effect of glucan on survival of 5-month-old female NZB/NZW F1 mice. A. Glucan group (घ). B. Saline group $(\boldsymbol{\Delta})$.

pus evolution and did not show differences in ANA levels either before or after 14, 30, 60, and 90 days, with ANA titers between $1 / 10$ and $1 / 2,560$. When low ANA titers $(1 / 10 \leq$ ANA $\leq 1 / 80$ ) and high ANA titers (ANA > 1/80) were compared, high ANA titers were observed in glucan-treated animals after 14, 30 and 60 days, whereas the control animals presented high titers after 90 days. However, the differences between the treated and untreated groups were not statistically significant.

\section{Effect of Glucan on Murine Lupus Resistance to Experimental Peritonitis by Klebsiella pneumoniae}

No deaths were observed in lupus mice treated with glucan 24 hours before septic shock induction, in contrast to a mortality of $95.3 \%$ in the control group during the follow-up of 12 days. Glucan pretreatment provided protection against septic shock, and no death was observed during the first 72 hours (Group I). Animals treated with glucan soon after infection presented accumulated death rates of $80.9 \%$ and $95.2 \%$ within 24 and 72 hours, respectively (Group II). Only eight animals were submitted to posttreatment with glucan; $50 \%$ of them died within 4 hours and a similar number died within 24 hours (Group III). Lupus controls showed accumulated death rates of $71.4 \%, 90.4 \%$, and $95.2 \%$ at 24,48 , and 72 hours, respectively (Group IV), whereas nonautoimmune controls showed accumulated death rates of $10 \%$ and $20 \%$ at 24 and 48 hours, respectively (Fig. 3).

The glucan pre-treated animals died later, even though their survival rate reached $90.9 \%$ at the end of the experiment and control Balb/c mice had an $80 \%$ survival rate during the same period. No differences could be seen in mouse survival rates when the animals were submitted to concomitant and posttreatment against septic shock in relation to the lupus control animals, and at the end of the experiment, one animal in group II and one in group IV were still alive.

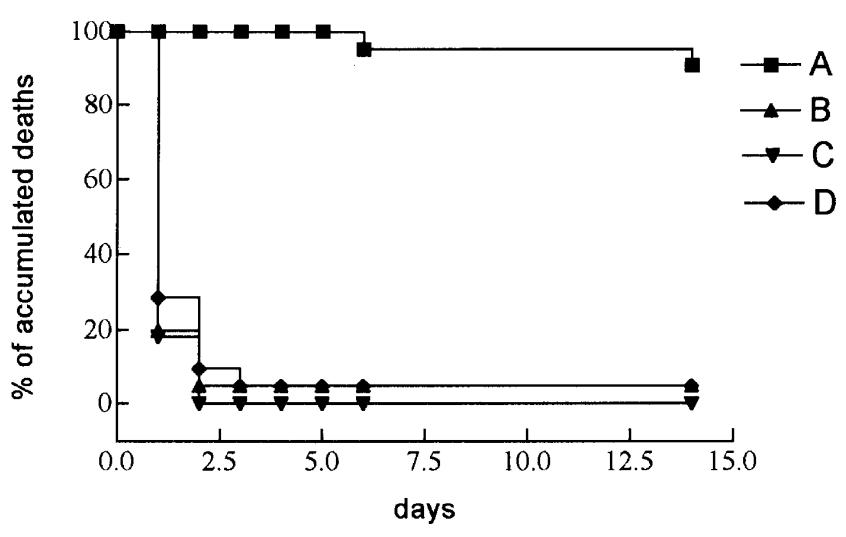

Fig. 3. Survival rate of glucan-treated and untreated NZB/NZW F1 mice submitted to induction of peritonitis with Klebsiella pneumoniae. A. Group I-animals pretreated with glucan 24 hours before bacterial injection (-). B. Group II-animals treated with glucan following bacterial injection ( $\mathbf{\Delta}$ ). C. Group III-animals posttreated with glucan 24 hours after bacterial injection $(\boldsymbol{\nabla})$. D. Group IV—animals injected with saline as control $(\diamond)$.

\section{DISCUSSION}

Glucan as a nonspecific stimulant of the MPS enhances host resistance to infections and neoplasms $(8,9,15,22,23)$. The use of immunostimulants is of controversial value in autoimmune diseases like lupus.

Female NZB/NZW F1 mice with manifestations of lupus show increased antibody levels and significant proteinuria followed within some weeks by glomerulonephritis with progressive renal failure. Approximately $50 \%$ of deaths occur at $8 \frac{1}{2}$ months of age and $90 \%$ at $9-13$ months $(1,24)$. Our findings show that glucan, when administered for short periods, is not likely to change the course of murine lupus. Conversely, when administered for long periods, it may accelerate the outcome of the disease.

Healthy and sick NZB/NZW F1 mice treated with glucan for 1 week did not show changes attributable to treatment. Glucan treatment for 3 months was not considered as a cause of death in young animals. However, old and sick animals submitted to treatment presented early deaths when compared to the controls. Actually, the evolution of murine lupus may be modified by administration of substances such as interferon inducers, leading to the appearance of autoantibodies in young NZB/NZW F1 mice and severe glomerulonephritis at the age of 4 months (25). Also, a number of immunogenic substances and lipopolysaccharide (26) are capable of inducing high ANA levels in young animals.

Glucan did not induce ANA in mice during the experiment. Two-month-old NZB/NZW F1 mice treated with glucan or saline for 3 months had the same ANA titers at 90 days, but sick animals receiving glucan for long periods of time showed a tendency to higher ANA titers. Glucan alone was unable to develop lupus activity, although in sick animals it may have exacerbated the hyperactive mechanisms of the disease. 
Our results demonstrate that glucan enhances resistance to septic shock induced by $K$. pneumoniae in previously glucantreated lupus mice. The MPS activation occurs within 24 hours and facilitates the infection control response. Thus no death was observed in the glucan-pretreated animals. However, a high mortality rate could be observed among animals receiving glucan immediately after the onset of infection.

It was clearly demonstrated that glucan is able to modify the response to infection, by enhancing host resistance in animals, even in the presence of active lupus disease. The beneficial effect of glucan in infection also has been previously demonstrated by one of us in humans (22).

\section{ACKNOWLEDGMENTS}

We are grateful to Dr. Sylvia Massiore, Rosalia R. de Lucca, Divaldo de Souza, and José A. Martins for animal care, and to Aparecido M. Oliveira, Maria C. Martino, Maristela A. Curi, and Suely N.A. Grosso for technical help, and to Dr. Neil F. Novo and Dr. Yara Juliano for the statistical analysis. These studies were supported by FAPESP.

\section{REFERENCES}

1. Theofilopoulos AN, Dixon FJ: Murine models of systemic lupus erythematosus. Adv Immunol 37:269-390, 1985.

2. Steinberg AD, Klinman DM, Kaster DL, Seldin MF, Gause WC, Scribner CL, Britten JL, Siegel JN, Mountz JD: Genetic and molecular genetic studies of murine and human lupus. J Rheumatol 14(suppl. 13): 166176,1987

3. Russel PJ, Steinberg AD: Studies of peritoneal macrophage function in mice with systemic lupus erythematosus: depressed phagocytosis of opsonized sheep erythrocytes in vitro. Clin Immunol Immunopathol 27:387-402, 1983.

4. Jacob CO, McDevitt HO: Tumor necrosis factor- $\alpha$ in murine autoimmune lupus nephritis. Nature 331:356-358, 1988.

5. Dore-Duffy P, Guha A, Rothman BL, Zurier RB: Synthesis of prostaglandin $\mathrm{E}$ by peritoneal macrophages from NZB/W mice. Life Sci 42:2669-2676, 1988.

6. Hassid WZ, Hoslyn MA, McCready RM: The molecular constitution of an insoluble polysaccharide from yeast Saccharomyces cerevisiae. J Am Chem Soc, 63:295-298, 1941.

7. Wooles WR, Di Luzio NR: Reticuloendothelial function and immune response. Science 142:1078-1080, 1963.

8. Di Luzio NR: Update on the immunomodulating activities of glucans. Springer Semin Immunopathol 8:387-400, 1985.

9. Franék, Malina J, Krátká H: Bacterial infection modulated by glucan: a search for the host defense potentiation mechanisms. Folia Microbiol (Praha) 37:146-152, 1992.
10. Wooles WR, Di Luzio NR: The phagocytic and proliferative response of the reticuloendothelial system following glucan administration. $J$ Reticuloendothel Soc 1:160-169, 1964.

11. Di Luzio NR, Morrow HS III: Comparative behavior of soluble and particulate antigens and inert colloids in reticuloendothelial-stimulated or depressed mice. J Reticuloendothel Soc 9:273-287, 1971.

12. Sherwood ER, Williams DL, McNamee RB, Jones EL, Browder IM, Di Luzio NR: Enhancement of interleukin-1 and interleukin-2 production by soluble glucan. Int J Immunopharmacol 9:261-267, 1987.

13. Doita M, Rasmussen LT, Seljelid R, Lipsky PE: Effect of soluble aminated $\beta$-1,3-D-polyglucose on human monocytes: stimulation of cytokine and prostagladin $\mathrm{E}_{2}$ production but not antigen-presenting function. $J$ Leukoc Biol 49:342-351, 1991.

14. Reynolds JA, Kastello MD, Harrington DG, Crabbs CL, Petters CJ, Jemski JV, Scott GH, Di Luzio NR: Glucan-induced enhancement of host resistance to selected infectious diseases. Infect Immun 30:51-57, 1980.

15. Di Luzio NR, Williams DL, Sherwood ER, Browder IW: Modification of diverse experimental immunosuppressive states by glucan. Surv Immunol Res 4:160-167, 1985.

16. Holbrook TW, Cook JA: Immunization of mice against Leishmania donovani by subcutaneous injections of dead promastigotes. Am J Trop Med Hyg 32:51-53, 1983.

17. Snyder AR, Levine S: Modulation of experimental allergic encephalomyelitis with yeast glucan and methyl palmitate to alter the activity of the reticuloendothelial system. J Reticuloendothel Soc 28:49-54, 1980.

18. Pérez HA, Bolivar J, San Blas G: The immunomodulatory effect of yeast glucan on delayed hypersensitivity. J Immunopharmacol 6:305-321, 1984.

19. Pospísil M, Tkadlecek L, Netíková J, Pipalová I, Viklická S, Kozubik A, Vácha J, Jarý J; Interstrain differences in the responsiveness of mice to glucan with respect to hematological effects and manifestations of late damage. Exp Pathol 33:27-33, 1988.

20. Staples PJ, Talal N: Relative inability to induce tolerance in adult NZB and NZB/NZW F1 mice. J Exp Med 129:123-139, 1969.

21. Norins LC, Holmes MC: Antinuclear factor in mice. J Immunol 93:148154, 1964.

22. de Felipe Júnior J, da Rocha a Silva Júnior M, Maciel FMB, Soares AM, Mendes NF: Infection prevention in patients with severe multiple trauma with the immunomodulator $\beta$ 1-3polyglucose (glucan). Surg Gynecol Obstet 177:383-388, 1993.

23. Babineau TJ, Marcello P, Swails W, Kenler A, Bistrian B, Forse RA: Randomized phase I/II trial of a macrophage-specific immunomodulator (PGG-glucan) in high-risk surgical patients. Ann Surg 220:601-609, 1994.

24. Dubois EL, Horowitz RE, Demopoulos HB, Teplitz R: NZB/NZW mice as a model of systemic lupus erythematosus. JAMA 195:285-289, 1966.

25. Steinberg AD, Baron S, Talal N: The pathogenesis of autoimmunity in New Zealand mice. I. Induction of antinucleic acid antibodies by polyinosinic-polycytidylic acid. Proc NatlAcad Sci USA 63:1102-1107, 1969.

26. Theofilopoulos AN, Shawler DL, Eisenberg RA, Dixon FJ: Splenic immunoglobulin-secreting cells and their regulation in autoimmune mice. J Exp Med 151:446-466, 1980. 